\title{
Experts blame feds for pharma corruption
}

Cite as: CMAJ 2017 February 27;189:E327-8. doi: 10.1503/cmaj.1095384

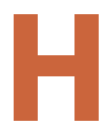
ealth Canada, not drug companies, should be held primarily responsible for misconduct in Canada's pharmaceutical industry, said policy experts at an anti-corruption symposium in Toronto.

There are many shades of pharma corruption, according to the World Health Organization, from exaggerating or hiding safety and effectiveness data to seeking shortcuts in regulation and bribing prescribers.

But wagging fingers at companies for taking the fullest advantage of flawed regulation and lax enforcement is missing the point, said Marc-André Gagnon, an associate professor of public policy at Carleton University in Ottawa. Corruption is "endemic" because it's profitable, and companies that "refuse to play the game" lose their market share, he explained. "Don't blame the companies," because it's up to governments to make sure crime doesn't pay.

Global spending on medicines is expected to reach $\$ 1.4$ trillion by 2019 . But as government budgets have tightened and the development of truly innovative drugs has slowed, manipulating demand for a higher volume of lowerimpact medicines "has become more profitable than producing effective drugs," said Gagnon. Without strong oversight, this shift from quality to volume creates an incentive to put drugs into the market that are unsafe, lack efficacy or provide minimal new benefit.

Dr. Joel Lexchin, a professor of health policy at York University in Toronto, agreed. "The best we can hope for from the pharmaceutical industry is that it obeys the law," he said. The task of protecting the public falls to Health Canada, "but I think through its cooperation with industry, that interest has become subverted."

\section{Who pays the piper?}

Since funding cuts in the mid-nineties, Health Canada has come to rely on user fees from the pharmaceutical industry to cover about $40 \%$ of drug regulation costs. At the same time, the speed and number of drug approvals have increased as part of a government-wide initiative to reduce regulatory burden on businesses.

Lexchin said these changes ushered in a new service relationship with pharma, made explicit in a 1997 internal bulletin. Dann Michols, then director general of Health Canada's Therapeutic Products Programme, advised staff that, in many cases, their "client" is the "person or company who pays" for a product review.

"When you're a department of health, making these kinds of pro-industry arguments shouldn't be within your mandate," said Lexchin.
Complicating the picture, Health Canada has to reduce the fees it charges industry if the department takes longer than an average 300 days to review new drugs. A study of a similar system in the United States suggests that pressure to meet the deadline may compromise the review. Drugs approved within 60 days of the US deadline were five times more likely to be hit with a safety warning once they were on the market.

"The reason there is pretty obvious," said Lexchin. "You're worried you're not going to be able to get the review done in time, so you start to overlook things."

Dr. Supriya Sharma, chief medical officer at Health Canada, dismissed the possibility that pressure to meet "service standards" in order to secure industry fees would bias the drug review.

"It's a bit ridiculous that we would be

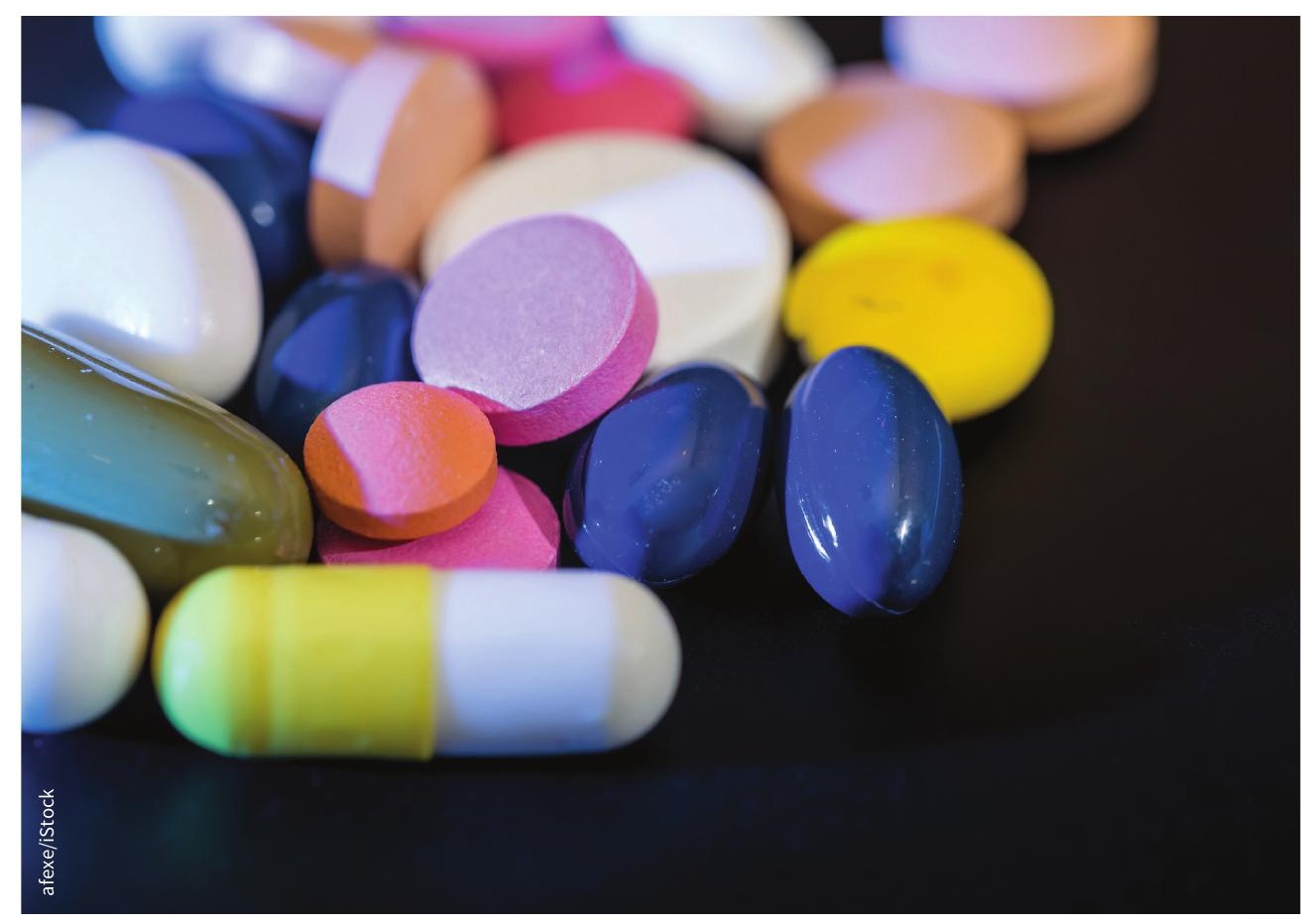

Health policy experts expressed concern that Health Canada is putting business interests before public protection. 
complicit in anything that would undermine or compromise the safety and efficacy of the products we're approving," she said. Even beyond their role as public servants, Health Canada staff "may either need to use these medications or have family or friends that would use them."

Sharma agreed that products approved through Health Canada's 180-day expedited process tend to have more safety issues once they're on the market. But these products are eligible for quick review because they offer a major benefit, so "the tolerance for risk is different as well."

She also noted that Health Canada recovers less than half its budget through industry fees, while drug regulators in the United States, Australia, the United Kingdom and the European Union recover $75 \%-100 \%$ of their costs this way.

"Ten percent of the reviews we do can go beyond deadline," Sharma added. "Meeting your deadline is not the priority; the priority is doing a complete and thorough and rigorous review."

\section{Transparency worries}

Lexchin and others at the anti-corruption symposium said Health Canada's secrecy makes it difficult to assess the quality of the review.

Most of the process is closed to the public and Health Canada closely guards the drug safety and efficacy information it receives from companies. This has been a safety risk in the past, such as when doctors were widely prescribing selective serotonin reuptake inhibitors to teenagers, and
Health Canada didn't disclose the evidence it held of harms to that age group.

The government recently passed the Protecting Canadians from Unsafe Drugs Act, also known as Vanessa's Law, which was designed to bring more transparency to the system. However, implementation of the law's reforms has stalled. "Health Canada is currently putting so many restrictions on your ability to get this information," Lexchin explained. "The law isn't going to provide much benefit."

Sharma said Health Canada is trying to share more, but when it comes to trade secrets, "we are bound to keep that confidential." By Health Canada's definition, that includes any information that a drug company has kept secret and that might affect their business. In such cases, it would be better if health professionals and researchers asked the company for the information, Sharma said. "That's the way we would prefer, instead of being the intermediary."

Dr. Sidney Wolfe, a former member of the US Food and Drug Administration's Drug Safety and Risk Management Committee, argued this approach isn't justified, particularly when similar data are made public in the US.

\section{Solutions for corruption}

Canadians need to know that Health Canada is putting business interests over public interests, Wolfe said. "The public perception now is that they're being protected by Health Canada. It's a complete misperception."
Public pressure and appeals to members of Parliament can be effective tools for change in this case because Health Canada is "subject to public opinion and funding," he said.

One way Health Canada could discourage pharmaceutical misconduct is to levy larger fines, said Gagnon. All the fines levied on drug companies in the US since 1991 total "less than half the profits of the 10 major drug companies in one year," added together.

Sharma agreed that fines have been too low to pose a deterrent to corruption. Until recently, "the maximum fine we could levy was $\$ 5000$," she said. Vanessa's Law now empowers the Health Minister to issue fines "in the millions."

Gagnon also suggested taxing pharmaceutical promotional spending. Italy has used the approach to generate 14 million euros a year for independent clinical trials. A similar tax in Canada could offset the cost of introducing value-based pricing, in which new drugs would be priced according to the benefit they bring to market. Gagnon explained this may curb corruption by encouraging a value-overvolume approach to drug development.

Wolfe said that public involvement will be critical to securing the political will to enact any solution against industry corruption. "Start informing the public," he urged participants in the meeting. "Health Canada is on pharma's side and that's unacceptable."

Lauren Vogel, CMAJ 